\title{
What can industry do to facilitate dietary and behavioural changes?
}

\author{
Johanna T. Dwyer* and Chung Mei Ouyang \\ Tufts University Schools of Medicine and Nutrition, and Jean Mayer Human Nutrition Research Center on Aging at Tufts \\ University, Box 783, New England Medical Center, 750 Washington St, Boston, MA, USA
}

\begin{abstract}
The food industry has five important roles in facilitating needed dietary and behavioural changes. Two of these roles are direct ones. Industry can increase the availability of a wide variety of basic commodities and new foods that help consumers meet dietary recommendations. It is also responsible for developing and formulating appealing, healthy and effective food products that decrease risks of chronic degenerative disease. Industry also plays an indirect role in facilitating dietary change by motivating consumers to select and prepare foods that will result in healthy dietary patterns. It can also participate in coalitions to facilitate other behaviours that decrease risks. Finally, it can collaborate actively in applied and fundamental research to further our understanding of the associations between food and health.
\end{abstract}

Industry: Nutrition: Diabetes: Metabolic syndrome: Chronic degenerative disease: Diet-related risk factors

\section{What changes are needed?}

Goals and strategies to achieve changes in diet and behaviour are best determined by evidence-based approaches that evaluate the strength of research evidence using agreed criteria, and draw conclusions based on it (Committee on Diet and Health, 1989). The risk factors associated with the metabolic syndrome must be reduced. Specific goals vary, depending on the risk factors that are present (DCCT Research Group, 1993; Diabetes Prevention Program Research Group, 1999; Wing, 1999). They usually include achieving and maintaining blood glucose levels as near normal as possible, achieving and maintaining healthy weights, optimizing lipid and blood pressure levels, and increasing physical activity (Purnell \& Brunzell, 1999; Willett et al. 1999; Wylie-Rosett, 1999). Quality of life, as well as these metabolic priorities, must also be considered (Franz, 1999a).

\section{What is industry's role?}

Table 1 summarizes steps that the food industry might take to bring about dietary changes. The food industry has an important role to play. However, the most potent measures also involve other players, including consumers and government. For example, nutritional measures that can help to normalize blood glucose levels are as follows, in descending order by their likely efficacy.

(1) Cultural re-engineering to achieve weight control by modifying environmental factors, including too much food and too little physical activity contributing to insulin resistance and other risks (Brand-Miller \& Colaguiri, 1996; Eaton et al. 1997; Neel, 1999).

(2) Adoption of dietary guidelines that stress achievement and maintenance of healthy food consumption practices.

(3) Increased availability of healthy foods that assist in meeting dietary guidelines for chronic disease prevention.

(4) Development of specially formulated foods with specific food ingredients that have beneficial effects, such as foods low in energy density, high in soluble/viscous fibre and resistant starch (RS), and low in saturated fat.

However, it is not individual foods, but overall dietary patterns and the food supply that must be changed to achieve health effects. Food policies that provide incentives to farmers and other food producers are also needed. It is apparent that industry cannot accomplish the most important of these measures by itself. The involvement of all sectors of society is necessary. This presentation focuses on dietary and behavioural strategies and actions applicable to producers of major food commodities, food manufacturers, retailers and food service establishments. Examples are chosen from the USA and emphasize measures that foster risk reduction associated with the metabolic syndrome.

\section{Make a variety of appealing foods available that help consumers to meet dietary recommendations}

Industry can make a wide variety of appealing traditional and new foods available that help consumers meet dietary 
Table 1. Industry strategies and actions for improving diet and health

\begin{tabular}{|c|c|}
\hline Strategy & Actions \\
\hline Increase availability of foods & $\begin{array}{l}\text { Provide choices in all settings with increased fibre and decreased saturated fat, sugar, sodium and } \\
\text { calories }\end{array}$ \\
\hline $\begin{array}{l}\text { Develop foods that decrease chronic } \\
\text { disease risk }\end{array}$ & $\begin{array}{l}\text { Test GI and develop satiety indexes of local foods/new foods and common meals. Hire personnel } \\
\text { knowledgeable in changing foods in more healthy directions }\end{array}$ \\
\hline $\begin{array}{l}\text { Motivate consumers to follow dietary } \\
\text { recommendations both at home and when } \\
\text { dining out. Include healthy choices in } \\
\text { homes, food service establishments, } \\
\text { catering, fast food outlets, institutions }\end{array}$ & $\begin{array}{l}\text { Support efforts to improve nutrition labels of processed foods and restaurant or fast-food meals. } \\
\text { Provide point-of-purchase information on nutritional value in supermarkets and food services. } \\
\text { Emphasize foods high in fibre and RS, low in sugars and calories. Avoid excess high carbohydrate } \\
\text { levels in sports bars, avoid excess high-calorie/low-fat and high-alcohol intakes }\end{array}$ \\
\hline $\begin{array}{l}\text { Join consortia to facilitate lifestyle and } \\
\text { behaviour changes other than diet }\end{array}$ & $\begin{array}{l}\text { Consortia are needed to help consumers avoid weight increases, keep healthy weights, support } \\
\text { long-term weight-control measures, and support physical activity and exercise. Consortia must } \\
\text { also address risk factors. In the USA these include the National Diabetes Education program, the } \\
\text { National Cholesterol Education Program and the National High Blood Pressure Education } \\
\text { Program. Information about risk factors, getting help and access to care and disease management } \\
\text { needs more widespread dissemination. Also support national health promotion and disease } \\
\text { prevention programs }\end{array}$ \\
\hline $\begin{array}{l}\text { Collaborate in research on foods, diets } \\
\text { and risk factors }\end{array}$ & $\begin{array}{l}\text { Type of fat and insulin resistance; satiety value and energy density of foods; utility of GI and } \\
\text { glycaemic load in predicting long-term blood glucose control; effects of substituting } \\
\text { monounsaturates or fatty acids high in saturated fats and carbohydrate and decreasing GI of foods } \\
\text { in diets of diabetics; type and amount of carbohydrate, fat, Gl satiety value, food consumption and } \\
\text { weight regulation over long term }\end{array}$ \\
\hline Increase variety of appealing foods & $\begin{array}{l}\text { Produce reasonable portion sizes. Market alternatives that are appealing and reasonably priced, } \\
\text { convenient and healthy (both traditional and new foods). Alterations in types of food may also be } \\
\text { needed }\end{array}$ \\
\hline
\end{tabular}

Modified with additions from FAO/WHO (1997).

recommendations. There are so many foods to choose from in most industrialized countries that both widespread food availability and educational strategies are necessary to assist consumers in making appropriate food choices. Supermarkets are in an ideal situation to do this.

Some of the products that need to be more widely available are old, familiar, basic, traditional commodities that are now packaged and marketed in more convenient forms. Producers of foods rich in whole grains, high in fibre, high in RS, low in saturated fat and calories, need to process them appropriately, make them more widely available, and communicate messages about these foods' health benefits. There is also a role for expanding the availability of 'new' traditional foods that are popular in other cuisines. For example, various types of frozen beans and peas packaged in convenient forms are now widely available in the USA. These steps may help to increase their consumption, with positive effects on health. Companies manufacturing foods that do not fit easily into the overall pattern may find it useful to alter individual items in healthier directions.

\section{Develop and formulate food products that decrease risks of chronic degenerative disease}

Industry can capitalize on scientific advances to develop appealing and affordable new foods that have demonstrable health benefits. Both plant breeding (either traditional or recombinant technologies) and food technology can be used to formulate such products. The alteration of the food supply requires less consumer motivation and behaviour change to bring about altered food consumption than do educational measures, making these strategies particularly appealing.

\section{Decreased food energy and energy density}

Food portion size influences the amount of calories and nutrients provided. Labelling of portion size and marketing of both processed and prepared foods in reasonable rather than super-sized portions would be helpful. Portion size information assists in counselling patients (Gillespie et al. 1998; Diabetes Prevention Program Research Group, 1999). The portion sizes specified on most processed foods are similar to those used in American food-exchange lists, making it easy to link teaching of portion sizes to easily available consumer information. However, they differ from portions specified in other nutrition education tools, such as the US Department of Agriculture's food pyramid guide. Greater harmonization of these educational materials is needed. Also, many consumers are unaware that these specified portion sizes are often smaller than those commonly eaten by Americans or served in restaurants and catering establishments. Fatty, sugary foods, foods low in water content and fibre, and alcoholic beverages are all high in energy density. Foods with decreased energy density that are satiating would be especially helpful. Prepared lowcalorie, macronutrient-modified entrees and other caloriereduced convenience foods are often low in fat, saturated fat, sodium and sugar. They are popular in the USA, their consumption is growing, and they offer options that may be helpful to some consumers in weight management. Recently, a major food company in the USA produced an entire line of such foods which, when consumed as part of a weight-loss regimen, brought demonstrable benefits in weight loss and control of other risk factors. However, prices for the line were high and marketing proved difficult. Unfortunately, use of low-calorie products does not automatically lead to weight control or healthier dietary patterns 
because caloric compensation occurs. Moderation in overall food intake is also necessary.

\section{Modifications in carbohydrates}

Ingredients and processing techniques are available to alter the amount, type and processing of carbohydrates so as to slow their absorption (Nuttall \& Gannon, 1991). Some products can be reformulated to be lower in sugars. Some sugar alternatives and substitutes that are currently available in the USA include high-intensity artificial sweeteners, polyols (sugar alcohols) and natural sweeteners (Schiweck \& Ziesenitz, 1996) that are used both as food ingredients and alone as table-top sweeteners. Some of these ingredients do not raise blood glucose levels at all, and others do so no more than other ingredients containing sugar.

The amount and type of starch or oligosaccharides in foods can also be changed. Other than amount, modifiable factors that influence the blood glucose responses produced by starch include structural characteristics, amylose/amylopectin ratios, whether the starch is raw or cooked, degree of starch gelatinization, temperature, processing (cracking, other alterations in particle size, gelatinization, extrusion, toasting), and the presence of other constituents such as fat, fibre, fluid and protein. These factors all affect the glycaemic index (GI) of foods. Representative GI values have been published for about 200 foods (Foster-Powell \& Miller, 1995) Resistant starches resist enzymatic digestion and are not absorbed in the small intestine. Some foods, such as beans, have a low GI and high RS, while others, such as corn flakes, have a high GI and a relatively high RS. Starch of the RS1 type consists of physically inaccessible starch such as that in seeds, whole corn, partially milled grains and leguminous seeds; RS2 consists of resistant starch granules in foods such as raw potato, green banana, high-amylose corn starch, and other foods with high amylose-to-amylopectin ratios (FAO/ WHO, 1997). The digestible starch in foods such as beans and lentils tends to be absorbed more slowly from the gut (Jenkins \& Wolever, 1981). In contrast, raw ordinary corn starch has a very low GI despite the fact that it is more or less fully absorbed (has low RS content). Plants can be bred by conventional techniques or produced by genetic engineering to have high amylose-to-amylopectin ratios, and ingredients can also be chosen to produce starches with high amylose content that are resistant to digestion. Products made with very high-amylose corn (maize), which is very high in RS2, are popular in Australia and are widely available there. RS3, retrograded starch, is produced by processing techniques that result in retrograded crystalloids which are poorly absorbed. RS4 is chemically modified starch that contains cross-bonded starch esters and ethers which slow absorption.

Some new products with modified starches are being marketed today in the USA to persons with insulin-dependent diabetes (O'Connell, 1999). They all contain ingredients such as soluble dietary fibre (guar gum) or RS (uncooked high-amylose corn starch), have a relatively low GI, list diabetes exchanges on their labels, and are low in fat, saturated fat, cholesterol and calories (approximately $130-150$ calories per bar). Most are fortified with micronutrients (O'Connell, 1999). For individuals who wish to have bars for breakfasts or snacks, these products cause less of a postprandial blood glucose rise than do other quick carbohydrate snacks. Thus they may be a good alternative for such patients, although they still increase blood glucose and energy intake more than eating nothing, and they are relatively expensive (O'Connell, 1999). Other sports bars, nutrition supplement bars, diet bars and granola bars on the market tend to be higher then the special 'diabetes' bars in calories and carbohydrate (without special ingredients aimed at blood glucose control) and may be useful for long-term, extreme endurance-type physical activities, but they provide no particular performance advantage for most individuals (FAO/WHO, 1997). If they are used by persons with diabetes they should be accompanied by blood glucose monitoring, since people vary in their blood glucose responses.

\section{Non-starch polysaccharides can also be modified}

Viscous, soluble fibres from leguminous seeds and gums form gels that modify viscosity, delay gastric emptying and help to decrease postprandial rises in blood sugar (Jenkins \& Wolever, 1981; Jenkins, 1991). High-fibre cereals or pastas enriched with soluble fibres, such as psyllium and other products formulated with guar gum, insoluble fibres and lignins are now available. They show promise because such staple foods are frequently consumed in relatively large amounts.

\section{Type and amount of fat}

The effects of type and amount of fat have been well described in this symposium and elsewhere (Purnell \& Brunzell, 1999). Saturated fat contributes to dyslipidaemia in diabetes. Monounsaturates have little effect on blood lipids and may improve blood glucose control when substituted for carbohydrates (Purnell \& Brunzell, 1999). Fat, saturated fat and caloric intakes can be altered by changes in recipes and also by using ingredients that reduce or replace fats. Some of these ingredients are carbohydrates with varying carbohydrate content, bioavailability, and caloric value. Others consist of proteins or other substances (Powers, 1999). Both low-fat diets (30\% of total calories), and diets with higher levels of total fat but low in saturated fat and enriched in monounsaturates, appear to improve glucose tolerance and lipid levels. Various fats differ in their composition. The optimal blend of fats is still being debated, although all experts concede that low levels of saturated fat are desirable. There is considerable interest in the beneficial effects of omega 3 fatty acids, and ratios of omega 3 to omega 6 fatty acids (Purnell \& Brunzell, 1999). Table 2 describes various fats.

Micronutrients in foods or supplements do not have a major role in blood glucose homeostasis (Franz, 1999a,b). Chromium supplements may have a role in persons with marginal glucose intolerance, but more clinical trials are needed before this finding can be regarded as secure (Franz, 1999b). Magnesium supplements do not appear to be beneficial (American Diabetes Association, 1992). Vitamin and mineral supplementation is most useful when a specific deficiency exists (Mooradian et al. 1994). 


\section{Inhibitors of digestive enzymes}

Medications that alter enzymes involved in starch digestion can reduce the rate of carbohydrate absorption and glycaemic response. Acarbose (an alpha glucosidase inhibitor) and miglitol are two such products (Caspary et al. 1986). Alpha amylase inhibitors have not proven to be useful.

\section{Motivate consumers to select and prepare foods that result in healthy dietary patterns}

Industry plays a role in supporting and communicating information that helps consumers adopt eating patterns to decrease risks of diet-related chronic degenerative diseases. Consumers need to know appropriate eating patterns, what foods to emphasize and why, and steps to take toward a healthy lifestyle. Although nutrition tools are designed for the general public, they help to guide American consumers at risk for metabolic syndrome toward more healthy eating patterns.

\section{Dietary guidelines}

Dietary guidelines provide recommendations that policymakers and consumers can use to reach health objectives. The Dietary Guidelines for Americans (USDA/USDHHS, 1995) are currently being evaluated and modified to make them more actionable. At present they are: (1) eat a variety of foods; (2) balance the food you eat with physical activity; maintain or improve your weight; (3) choose a diet with plenty of grain products, vegetables and fruits; (4) choose a diet low in fat, saturated fat and cholesterol; (5) choose a diet moderate in sugars; (6) choose a diet moderate in salt and sodium; and (7) if you drink alcoholic beverages, do so in moderation.

\section{The food pyramid guide}

The US Department of Agriculture's food pyramid guide provides consumer information on healthy choices that meet the Dietary Guidelines for Americans and the recommended dietary allowances of nutrients (USDA/USDHHS, 1995) The Pyramid pattern is higher in dietary fibre and micronutrients, but lower in simple sugars, fat, saturated fat, cholesterol and sodium than is the current American pattern of food consumption. Current US policy is to promote and replicate the pyramid pattern. The USDA Pyramid recommends that added sugars be limited to $40 \mathrm{~g}$ (10 teaspoons) per day on a 2000-calorie diet, and fat be limited to $30 \%$ of calories. If Americans altered their consumption practices to follow the Pyramid recommendations more closely, positive health effects would be likely (Frazao, 1996). However, adjustments in agricultural production in several commodity sectors, trade, prices, and non-food uses would also be likely (Young \& Kantor, 1999). Intakes of caloric sweeteners and fats and oils would decrease. Although Americans already consume the minimum number of servings of grains specified, the type of grains or food uses of grains might vary. Meeting recommendations for vegetables would require alterations in the types and quantities of vegetables consumed, with a quadrupling of production of dark green leafy and deep yellow vegetables, a tripling of dry beans, peas and lentils, and fewer servings of starchy vegetables such as potatoes.

A variant on the pyramid employed in the Dietary Approaches to Stop Hypertension (DASH) study, is now being implemented in a community intervention trial after satisfactory results in a feeding study (Appel et al. 1997). This plant-based diet rich in fruits, vegetables, low-fat dairy products with reduced saturated fat, total fat, and sodium brought about sizeable reductions of blood pressure in both hypertensives and non-hypertensives at constant weights, and positive changes in other risk factors as well.

\section{Serving sizes}

Serving sizes are specified on the nutrition facts labels for processed foods in the USA. However, the standard serving sizes provided are smaller than many consumers actually eat. Many consumers need guidance on the portion sizes they eat.

\section{Food labelling}

Consumers want to know and can ascertain for themselves how a product looks, what it tastes like and what it costs. They must rely on standards and regulations for information on other relevant characteristics, including nutrient content and the validity of health claims.

\section{Ingredient and nutrient labelling}

In the USA, labelling information on processed foods includes ingredient lists and a 'Nutrition Facts' label listing total fat, saturated fat, cholesterol, sodium, total carbohydrate, dietary fibre, sugars and protein. Combined with information about the type of food, the nutrition facts label and other labelling information provide an easy way for consumers to choose foods on the basis of their nutrient characteristics such as carbohydrate, saturated fat and fibre content. At present, certain ready-to-eat foods such as unpackaged bakery items, restaurant and take-out food, and many raw foods such as fresh fruits and vegetables are not required to provide the nutrient composition on their labels. Some supermarkets voluntarily provide this information. Extending nutrient labelling to these foods or to menus would be helpful.

Sugared soft drinks, fruit drinks, cookies, candy and sugared breakfast cereals are examples of foods that are high in added sugars. Nutrient fact labels presently disclose total carbohydrate and sugars in grams, but do not state a daily value standard against which sugar intake can be judged. Also, they disclose information about naturally occurring sugars, but do not include information on how much sugar has been added by processors. Currently a petition is under consideration by government authorities which seeks to require that nutrition labels also include the amount of sugar in grams that has been added to foods, using a daily value of $40 \mathrm{~g}$. The nutrient fact labels at present do not provide information on the type and amount of RS included, although non-starch polysaccharides and RS 3 are labelled as fibre. 


\section{Nutrient content claims}

The ability to make a health claim or to label a product with a nutrient content claim referring to calories, fat, saturated fat, sugars, fibre or other nutrients can provide marketers with a competitive edge for promoting healthier foods. The words used in nutrient content claims must conform to certain regulatory standards and specifications.

\section{Health claims on food labels}

Industry has a role in developing new health claims, adhering to appropriate standards and supporting regulatory actions. Evidence-based reviews are used by regulatory agencies to assess whether sufficient significant scientific agreement exists to merit health claims. The Food and Drug Administration of the US Department of Health and Human Services has approved almost a dozen health claims on the associations of diet and disease relationships that may be used on food labels with appropriate qualifications. The relationships are: (1) dietary saturated fat and cholesterol and coronary heart disease; (2) sodium and hypertension; (3) dietary fat and cancer; (4) fruits and vegetables and cancer; (5) calcium and osteoporosis; (6) sugar alcohols and dental caries; (7) folate and neural tube birth defects; (8) fruits, vegetables and grain products that contain fibre, particularly soluble fibre and coronary heart disease; (9) whole grains and heart disease and cancer; (10) grain products, fruits and vegetables and cancer; and (11) foods that contain soluble fibre from whole oat or psyllium products and coronary heart disease. Several other health claims are now being considered, including one on soy protein and heart disease (approved in late 1999).

\section{Other educational tools}

A variety of additional educational tools are available that may help to achieve consistency in dietary intakes and blood glucose control for those with insulin resistance or diabetes. Some systems focus on calorie counting to help achieve weight reduction. Some focus on the amount of total carbohydrate (carbohydrate counting) or counting of total available glucose, others on the amount of carbohydrate and type of food (diabetes exchange lists, food pyramids and food choice lists; Franz, 1999b) or type of carbohydrate/ food composition (GI), such as lists of low-GI foods (e.g. legumes, pearl barley, whole grain or lightly refined grains, grains made from coarse flour, pasta, etc.; Brand-Miller \& Colaguiri, 1996). The GI is rarely used as a teaching tool in the USA, perhaps because with US nutrient and other labelling information it is easier to relate to carbohydrate counting and exchange lists (Beebe, 1999; Katanas, 1999). Studies are needed to demonstrate whether GI offers advantages for American patients to use in planning menus and learning to control their food intakes. The food and drug industries in many countries have provided very effective educational materials and tools, popularized messages associated with disease risk reduction, and disseminated basic and applied research findings to healthcare professionals. These efforts should continue, but must consider specific products in the context of overall dietary patterns.

\section{Join coalitions to decrease other chronic disease risk factors}

Nutrition is a social good. The food industry has a larger and even more important role in society than simply that of producing food. Industry also has an indirect role in forwarding the larger societal agenda of promoting health, and preventing and controlling disease. It can do this by supporting both population-based interventions and those targeted at high-risk groups. Partners include both government and non-governmental institutions, such as professional groups.

High-priority topics for such efforts include educational and informational campaigns about weight control, physical activity, prevention of chronic disease risks, and disease management.

Healthy weight is vital in controlling chronic disease risk (Willett et al. 1999). In persons who are overweight or obese, weight reduction of $5-20 \%$ of body weight decreases elevated blood glucose, blood pressure and plasma lipid levels, including total and low-density lipoprotein cholesterol, and increases high-density cholesterol levels (NIH, 1998). In both overweight and normal-weight persons with impaired glucose tolerance, a low-calorie diet and increased physical activity decreased non-insulindependent diabetes incidence rates for diabetes at 6 years by 41-46\% over controls (Pan et al. 1997). In overweight persons with diabetes, even small amounts of weight loss (e.g. $2 \cdot 5-5 \mathrm{~kg}$ ) improve blood glucose levels and $\mathrm{HbAlc}$ levels measured 6-10 weeks later (Heller et al. 1988; Rouneraa et al. 1988; Agurs-Collins et al. 1997). One group hypothesizes that the reduction in carbohydrate intake that often accompanies energy restriction apparently may improve insulin sensitivity and glycaemia even before substantial amounts of weight are lost, but this remains to be determined (Markovic et al. 1998). Later changes in glycaemia and insulin sensitivity after weight loss occurs are probably more closely associated with decreases in abdominal fat (Markovic et al. 1998). However, achieving and sustaining weight loss over the long term is difficult, and more effective means are needed for long-term maintenance of weight at healthier levels.

Moderate to vigorous physical activity 3-5 days a week may decrease abdominal fat, increase cardiorespiratory fitness, and possibly help in maintaining weight loss (NIH, 1998). Physical activity also decreases risks of coronary heart diseases, hypertension, non-insulin-dependent diabetes and other conditions (Pate et al. 1996; USDHHS, 1996).

Some commercial weight-loss programmes, clinics, and health and exercise clubs offer weight-control options for consumers that combine diet and physical activity. An innovative weight-control program now available in the USA is 'Shape Up and Drop 10', an Internet-based, interactive self-help program focused on a comprehensive, completely individualized, interactive approach to weight management emphasizing diet and physical activity, that permits tracking and self-monitoring. Shape Up America! is a non-profit organization focused on fitness and founded by Dr Everett Koop, former Surgeon General of the USA. Shape Up also sponsors a free fitness centre on the web worldwide. 
Table 2. Examples of the monounsaturated and saturated fatty acid content of various fats

\begin{tabular}{lccl}
\hline & \multicolumn{3}{c}{ Saturated fatty acid content } \\
\cline { 2 - 4 } Monounsaturate content & Low $(10 \%$ or less $)$ & Moderate $(11-30 \%)$ & High $(\geqslant 30 \%)$ \\
\hline High $(\geqslant 30 \%)$ & Canola & Olive & Household vegetable shortening \\
& & Sesame seed & Palm \\
& & Peanut & Chicken fat \\
& & Soft tub margarine & Beef fat and mutton fat \\
Moderate $(11-30 \%)$ & Stick margarine* & Palm \\
& Salflower & Corn & Kemel oil \\
& Sunflower & Wheatgerm & Butter fat \\
& Walnut & \\
& & Soy & \\
Low $(10 \%$ or less $)$ & Cottonseed & Coconut \\
\hline
\end{tabular}

* High in trans fatty acids which behave like saturated fatty acids in the body. Source: adapted from $\mathrm{NIH}, 1987$.

In the USA, the National Diabetes Education Program, National Cholesterol Education Program, National High Blood Pressure Education Program and the Weight Information Network are collaborative efforts sponsored by the federal government. They join public, voluntary and private-sector efforts to raise awareness and provide information to both professionals and laypersons on the identification, prevention and treatment of these chronic degenerative diseases and conditions. Each program has both population-based components and targeted efforts for those who are already at high risk and their children. Industry is a critical partner in disseminating these efforts.

\section{Healthy People 2010}

Healthy People is the document that summarizes population-based health promotion and disease-prevention objectives to improve the health of Americans. A review of Healthy People 2000 was recently completed (National Center for Health Statistics, 1999) The proportion of the US population reporting physical activity has not changed much in the past decade, and the baseline level was already very low. Progress has been better in terms of the declines of coronary heart disease and stroke mortality, but much remains to be done (USDHHS, 1996). The reduction of racial and ethnic disparities in the complications of diabetes is a high-priority objective for Healthy People 2010. Industry can aid such efforts.

\section{Collaborate as a partner in research}

Finally, industry plays a role in collaborating in research to enhance our understanding of associations between diet and disease-risk factors. Industry is an essential partner for moving forward in fundamental and applied research. Research topics include more widespread dissemination of standardized analytical methods for defining carbohydrates in foods and for assessing the GI (FAO/WHO, 1997). Methods for assessing both short- and long-term satiety in a standardized manner must also be developed. Research is needed on whether the GI and glycaemic load of diets is useful in predicting long-term blood glucose control as measured by hemoglobin A1c, or other long-term outcomes such as decreased incidence of non-insulin-dependent diabetes. The effects of diets low in GI on blood pressure and blood lipids also need to be assessed (Salmeron et al. 1997; Diabetes Prevention Program Research Group, 1999) The effects on long-term outcomes of both substituting monounsaturated fats for carbohydrate and decreasing the GI of foods in the diets of diabetics also deserve attention (Storlien et al. 1998; Wolever, 1999). The relationships need to be clarified between the amount and type of carbohydrate or fat and such variables as GI, satiety value, energy density of foods, and long-term effects of food consumption and weight regulation.

\section{Conclusions}

In the 21 st century, research may reveal that carbohydrate composition is as important in its effects on digestion, absorption, ultimate metabolism and chronic disease risk as differences in energy balance, protein or fatty acid components proved to be in this century. Nutrition scientists and food technologists in industry now have the expertise needed to devise food products that help to control the risks of many chronic diseases, and must use it to improve health.

\section{Acknowledgements}

This material is based upon work supported in part by the US Department of Agriculture under agreement No. 581950-9-001. Any opinions, findings, conclusions or recommendations expressed in this publication are those of the author and do not necessarily reflect the views of the US Department of Agriculture. We thank Sharon Ployer for typing this manuscript.

\section{References}

Agurs-Collins T, Kumanyika S, Hove T \& Adams-Campbell L 
(1997) A randomized controlled trial of weight reduction and exercise for diabetes management in older African-American subjects. Diabetes Care 20, 1503-1511.

American Diabetes Association (1992) Magnesium supplementation in the treatment of diabetes (Consensus Statement). Diabetes Care 15, 1065-1067.

Appel L, Moore T, Obarzanek E et al. (1997) A clinical trial of the effects of dietary patterns on blood pressure. New England Journal of Medicine 336, 1117-1124.

Beebe C (1999) Diets with a low glycemic index: not ready for practice yet! Nutrition Today 34, 82-86.

Brand-Miller J \& Colaguiri S (1996) The carnivore connections: dietary carbohydrate in evolution of non-insulin dependent diabetes mellitus. Diabetologica 37, 1280-1286.

Caspary W, Lembcke B \& Creutzfeldt W (1986) Delay of carbohydrate absorption by glucosidase inhibitors. In Delaying Absorption as a Therapeutic Principle in Metabolic Diseases, pp. 87-96 [W Creutzfeldt \& U Folsch, editors]. Stuttgart: Georg Thieme Verlag.

Committee on Diet and Health (1989) Recommendations for reducing chronic disease risk of the Nation. In Diet and Health. Washington, D.C.: National Academy Press.

DCCT Research Group (1993) Nutrition interventions for intensive therapy in the Diabetes Control and Complications Trial. Journal of the American Dietetic Association 93, 768-772.

Diabetes Prevention Program Research Group (1999) The Diabetes Prevention Program: design and methods for a clinical trial in the prevention of type 2 diabetes. Diabetes Care 22, 623-634.

Eaton S, Eaton A \& Konner M (1997) Paleolithic nutrition revisited: a 12-year retrospective on its nature and implications. American Journal of Clinical Nutrition 51, 207-216.

FAO/WHO (1997) The role of the glycemic index in food choice. In Carbohydrates in Human Nutrition, Report of the Joint FAO/ WHO Expert Consultation, pp. 25-29. Rome: Food and Agricultural Organization.

Foster-Powell K \& Brand-Miller J (1995) International tables of glycemic index. American Journal of Clinical Nutrition 65, 871S-893S.

Franz M (1999a) A dietician's perspective on medical nutrition therapy. In American Diabetes Association Guide to Medical Nutrition Therapy for Diabetes, pp. 3-17 [M Franz \& J Bantle, editors]. Alexandria, Virginia, USA: American Diabetes Association.

Franz M (1999b) Micronutrients and diabetes. In American Diabetes Association Guide to Medical Nutrition Therapy for Diabetes, pp. 165-191 [M Franz \& J Bantle, editors]. Alexandria, Virginia, USA: American Diabetes Association.

Frazao E (1996) The American diet: a costly problem. Food Review 19, 2-6.

Gillespie S, Kulkarni K \& Daly A (1998) Using carbohydrate counting in diabetes clinical practice. Journal of the American Dietetic Association 98, 897-905.

Heller S, Clarke P, Daly H et al. (1988) Group education for obese patients with type 2 diabetes. Diabetes Medicine 5, 552-556.

Jenkins D (1991) Fiber and delayed carbohydrate absorption in man: lente carbohydrate. In Delaying Absorption as a Therapeutic Principle in Metabolic Diseases, pp. 45-60 [W Creuzfeldt \& U Folsch, editors]. Stuttgart: Georg Thieme Verlag.

Jenkins D \& Wolever T (1981) Slow release carbohydrate and treatment of diabetes. Proceedings of the Nutrition Society $\mathbf{4 0}$, $227-235$.

Katanas H (1999) Diets with a low glycemic index are ready for practice. Nutrition Today 34, 87-88.

Markovic T, Jenkins A, Campbell L, Furler S, Draegen E \& Chisholm D (1998) The determinants of glycemic responses to diet restriction and weight loss in obesity and NIDDM. Diabetes Care 21, 687-694.
Mooradian A, Faila M, Hoogwerf B, Isaac R, Maryniuk M \& Rosett JW (1994) Selected vitamins and minerals in diabetes mellitus. Diabetes Care 17, 464-479.

National Center for Health Statistics (1999) Healthy People 2000, Review 1998-99. Hyattsville, MD, USA: Centers for Disease Control and Prevention, US Department of Health and Human Services, National Center for Health Statistics, US Public Health Service.

NIH (1987) Facts about Blood Cholesterol. US Department of Health and Human Services, Public Health Service, National Institutes of Health.

NIH (1998) Clinical Guidelines on Identification, Evaluation and Treatment of Overweight and Obesity in Adults: Evidence Report. Expert Panel Report. Bethesda, MD: National Institutes of Health, National Heart, Lung and Blood Institute.

Neel J (1999) The 'thrifty genotype' in 1998. Nutrition Reviews $\mathbf{5 7}$, S2-S9.

Nuttall F \& Gannon M (1991) Plasma glucose and insulin response to macronutrients in nondiabetics and NIDDM subjects. Diabetes Care 14, 824-838.

O'Connell B (1999) The new diabetes snack bars: helpful or just hype? Diabetes Care and Education 20, 11-15.

Pan X, Li G, Hu Y et al. (1997) Effects of diet and exercise in preventing non-insulin dependent diabetes mellitus in people with impaired glucose tolerance: the Da Quing IGT and Diabetes Study. Diabetes Care 20, 537-552.

Pate R et al. (1995) Physical Activity and Public Health: Recommendation from the Centers for Disease Control And Prevention and the American College of Sports Medicine. Journal of the American Medical Association 273, 402-407.

Powers M (1999) Sugar alternatives and fat replacers. In American Diabetes Association Guide to Medical Nutrition Therapy for Diabetes, pp. 148-164 [M Franz \& J Bantle, editors]. Alexandria, USA: American Diabetes Association.

Purnell J \& Brunzell J (1999) Food fats and dyslipidemia. In American Diabetes Association Guide to Medical Nutrition Therapy for Diabetes, pp. 126-147 [M Franz \& J Bantle, editors]. Alexandria, USA: American Diabetes Association.

Ronnemaa T, Marniemi J, Puukka P \& Kuusi T (1988) Effects of long-term physical exercise on serum lipids, lipoproteins and lipid metabolizing enzymes in type 2 (non-insulin-dependent) diabetic patients. Diabetes Research 7(2), 79-84.

Salmeron N, Manson E, Stampfer M, Colditz G, Wing A \& Willett W (1997) Dietary fiber, glycemic load and risk of non-insulin dependent diabetes mellitus in women. Journal of the American Medical Association 277, 472-477.

Schiweck H \& Ziesenitz S (1996) Physiological properties of polyols in comparison with easily metabolisable saccharides. In Advances in Sweeteners, pp. 62-66 [C Grjnes, editor]. Glasgow: Blackie/Chapman \& Hall.

Storlien L, Tapsell L \& Calvert G (1998) Role of dietary factors in insulin resistance: macro-nutrients. International Life Sciences Institute Symposium (abstr., in press).

USDA/USDHHS (1995) Food and Your Health. USDA Dietary Guidelines for Americans. Washington, D.C.: US Department of Agriculture/US Department of Health and Human Services.

USDHHS (1996) Physical Activity and Health. A Report of the Surgeon General. Atlanta, GA: US Department of Health and Human Services, Centers for Disease Control and Prevention, National Center for Chronic Disease Prevention and Health Promotion.

Willett W, Dietz W \& Colditz G (1999) Guidelines for healthy weight. New England Journal of Medicine 341, 427-434.

Wing R (1999) Lifestyle and the prevention of diabetes. In American Diabetes Association Guide to Medical Nutrition Therapy for Diabetes, pp. 351-368 [M Franz \& J Bantle, editors]. Alexandria, Virginia, USA: American Diabetes Association. 
Wolever T (1999) Dietary recommendations for diabetes: high carbohydrate or high monounsaturated fat. Nutrition Today $\mathbf{3 4}$, 73-78.

Wylie-Rosett J (1999) Hypertension and medical nutrition therapy. In American Diabetes Association Guide to Medical Nutrition
Therapy for Diabetes, pp. 295-311 [M Franz \& J Bantle, editors]. Alexandria, Virginia, USA: American Diabetes Association.

Young C \& Kantor L (1999) Moving toward the food pyramid guide: implications for US Agriculture. In Nutrition Week, No. 29, pp. 4-6. Washington, D.C.: Community Nutrition Institute. 